\title{
Cybersickness Testing Of Gender And Experience Factors Using Virtual Reality
}

\author{
Ancella Hendrika ${ }^{*, a, 1}$, Clara Theresia ${ }^{b, 2}$, Thedy Yogasara ${ }^{c, 3}$ \\ a,b,c Universitas Katolik Parahyangan, Indonesia \\ ${ }^{1}$ ancella.hendrika@gmail.com*, ${ }^{2}$ claratheresia@unpar.ac.id, ${ }^{3}$ thedy@unpar.ac.id
}

\begin{abstract}
One of the technologies that people are starting to get interested in is virtual reality (VR). VR is widely used as a means of entertainment, even more so at this time, the e-sports industry is developing rapidly. However, the use of VR can cause cybersickness, a disease arising from sensory and perceptual mismatches between the visual and vestibular systems. The emergence of cybersickness can be related to gender and experience using VR. There have been studies on cybersickness, but the results obtained had not come to the same conclusion. This research aims to identify the effect of gender and experience using VR, predict the timing of cybersickness by using physiological measurements, and provide recommendations that can minimize cybersickness in activities using VR. The measuring instruments used in this research are galvanic skin response (GSR) and a simulator sickness questionnaire (SSQ). In this study, the influence test is conducted by using ANOVA and Kruskal-Wallis to determine whether gender and experience using VR affect the potential for cybersickness. Based on the GSR measurement results, it finds that gender and experiences of using VR do not affect a person's potential for cybersickness. From the result of SSQ measurement, gender does not affect cybersickness, but the experience of using VR affected a person's potential for cybersickness. Qualitatively, cybersickness symptoms appear in the 15-20 minutes after the VR game has set in. Therefore, it is recommended to limit the usage of VR to less than 15 to 20 minutes per session.
\end{abstract}

Keywords: cybersickness, galvanic skin response (GSR), simulator sickness questionnaire (SSQ), virtual reality

\section{INTRODUCTION}

In this era, technology is developing very rapidly and becoming more sophisticated. Human life is increasingly helped and facilitated by technology. One of the technologies that the public started paying attention to is virtual reality (VR). VR is a tool that can unite the world of technology and can present nature in a wide field. In technical terms, VR is used to describe a three-dimensional environment that is generated by a computer and can interact with humans [1]. VR has great potential to be developed and applied in several fields, such as education, industry, trade, entertainment industry, and others.

The revenue from VR sales in the United States has continued to increase since 2014 and will continue to increase in the following years [2]. In 2018 it was estimated that VR users had reached 171 million people [3].

Indonesia is a developing country that in everyday life cannot be separated from the use of technology. According to Newzoo [4], Indonesia is one of the largest video game markets in the Asia Pacific with sales reaching $\$ 1.1$ billion. Seeing this figure, it is not surprising that the e-sports industry, in particular, will grow in Indonesia. Moreover, e-sports has now become one of the sports that are competed in the SEA Games [5], and $15 \%$ of internet users are fans of e-sports [6]. Besides, overall video game viewers will increase worldwide. In 2018 there were 750 million people playing video games, and it is predicted that this will increase to more than one billion people by 2022 [4].

The growing use of VR, especially in the e-sports field, has made developers focus on creating a comfortable virtual environment. This happens because the longer a person's senses are exposed to the virtual world, the more susceptible the person suffers due to exposure to these technologies. VR can create immersive experiences, where technology blurs the boundaries between the real world and the digital world so that users can experience an atmosphere and sensation like the real world. Unfortunately, VR has limitations where the human body will experience conditions such as driving drunkenness or feeling like being swayed on a ship. Sometimes a person seeing visual movement can get a feeling of being unwell, even without body movement [7]. Disease caused by sensory and perceptual incompatibility between the visual and vestibular systems is called cybersickness [8]. Cybersickness is a symptom of discomfort such as weakness, not being fit, and feeling sick due to exposure to virtual reality. Sometimes, people experiencing cybersickness psychologically are still carried away by the false atmosphere caused by virtual reality, although in reality the person has returned to the real world [9]. Research on cybersickness is important because at least $60 \%$ of people who firstly use VR experience some degree of cybersickness symptoms [10], [11].

This research will focus on e-sports to see an opportunity to develop the use of VR in the world of esports. E-sports is dominated by players aged between 1624 years old [6]. Meanwhile, a person's susceptibility to motion sickness increases at the age of 12 to 21 years old and over time it begins to decline. It will increase again when the person is 50 years old [12]. Therefore, this study will focus on men and women aged between 21-24 years old since people under 21 years old or above 50 years old are exposed to cybersickness at the beginning of the use of 
virtual reality. In fact, under normal circumstances, it should not be like that.

The occurrence of cybersickness is related to gender and experience using VR. Table 1 shows the previous state-of-the-art research on cybersickness. Based on previous studies, there were no results that stated the same conclusions, and there was still a research gap between these studies. Also, there were not many studies that use the experience factor. Based on this background, the objectives of this research are identifying the influence of gender and experience using VR on potential exposure to cybersickness, identifying predictions of the time of cybersickness by utilizing physiological measurements, and providing recommendations to minimize the occurrence of cybersickness in activities using VR. Based on this background, the objectives of this research are identifying the influence of gender and experience using VR on potential exposure to cybersickness, identifying predictions of the time of cybersickness by utilizing physiological measurements, and providing recommendations to minimize the occurrence of cybersickness in activities using VR.

Table 1. State of the Art Research of Cybersickness

\begin{tabular}{|l|c|c|}
\hline \multicolumn{1}{|c|}{ Research } & Factor & Results \\
\hline Clemes and Howarth [13] & Gender & Effected \\
\hline Park et al. [14] & Gender & Effected \\
\hline Knight and Arns [15] & Gender & Not Effected \\
\hline Gamito et al. [16] & $\begin{array}{c}\text { Gender; } \\
\text { Experience }\end{array}$ & $\begin{array}{c}\text { Effected; } \\
\text { Effected }\end{array}$ \\
\hline Ling et al. [17] & Gender & Not effected \\
\hline Sagnier et al. [18] & $\begin{array}{c}\text { Gender; } \\
\text { Experience }\end{array}$ & $\begin{array}{c}\text { Not affected; } \\
\text { Not effected }\end{array}$ \\
\hline
\end{tabular}

\section{RESEARCH METHOD}

In this study, there are several tools used, namely:

1. Oculus Rift S VR device that consists of one headset and two stick controllers that require AA batteries to operate. The headset requires energy from the computer via a display port cable and USB 2.0. Figure 1 shows the Oculus Rift $S$ type VR headset used by one of the participants.

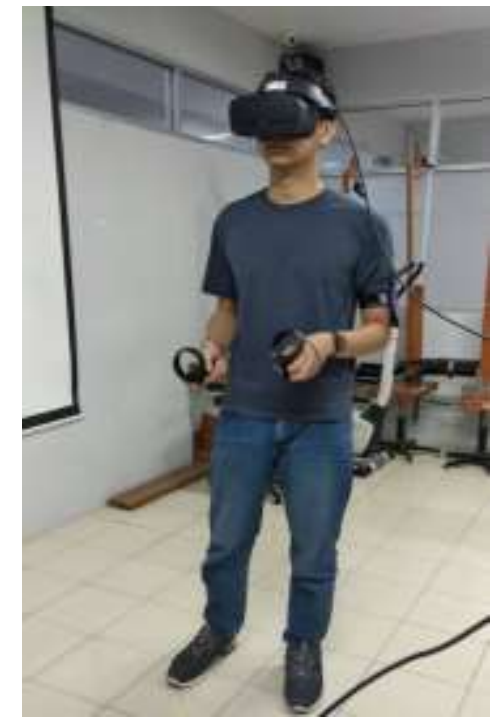

Figure 1. Oculus Rift $S$

2. Computer devices with Intel i7 $8700 \mathrm{~K}$ processor specifications, NVIDIA RTX 2070 graphics card, and 32 GB RAM

3. 22-inch LCD monitor screen. This LCD monitor is used by researchers to control the display in VR so that participants do not need to remove the VR if the researcher needs to adjust or change the task that being carried out.

4. Galvanic skin response and eSense application to measure sweat levels (in figure 2). The eSense application can be downloaded at the Play Store service application store for Android devices and the App Store for iOS devices.

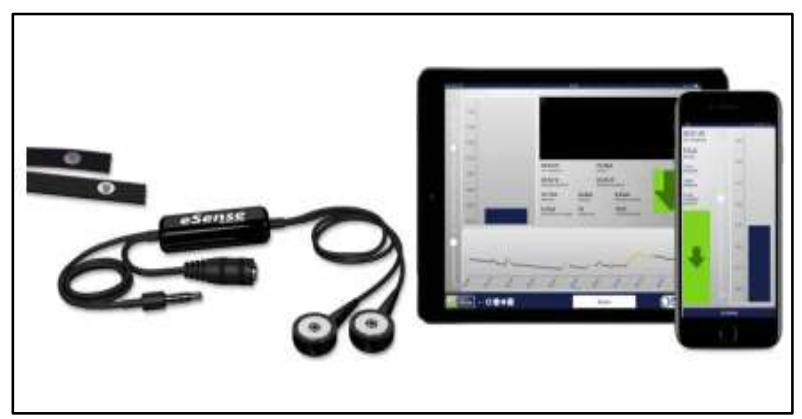

Figure 2. GSR and eSense Application [19]

5. Software that consists of Oculus, Steam, and the Beat Saber game. Oculus software is required to run VR devices, while Steam software is required to download the Beat Saber game (in figure 3) 


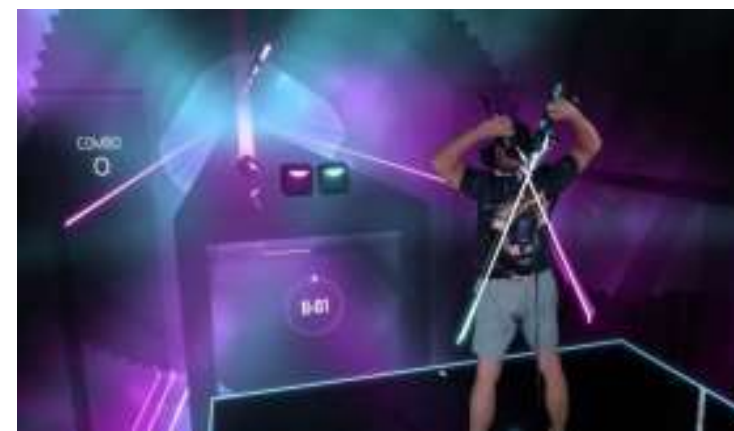

Figure 3. Beat Saber Display [20]

The experimental design is carried out by determining the independent and dependent variables in the study, and the criteria and number of participants in the experiment. The design of the experimental activities are carried out by each participant.

At the time of collecting data, participants are first explained what tasks will be carried out. After that, participants will fill out a consent form which contains a statement that the participants are willing to be involved in the research and understand what should and should not be done during data collection. The instruments used in data collection were GSR and SSQ. Before carrying out the activities, the participants' sweat levels are first measured for 10 minutes using GSR, and participants are also asked to fill in the SSQ according to their body conditions before doing activities using VR. Furthermore, the participants perform the assigned tasks using VR for approximately 20 minutes. After doing the activities, the participants' sweat levels are measured again for 10 minutes and the participants returned to fill in the SSQ according to their body condition after doing the given task. If during the activities the participants are not strong enough to continue the assigned task, the data collection for these participants will be stopped.

Data collection is carried out at the Laboratory of Work Design Analysis and Ergonomics, Parahyangan Catholic University, Bandung. The data collection is also carried out on 35 participants using the purposive sampling technique. The participants consist of 12 male participants who have never used VR (A1B1), nine male participants who have ever used VR (A1B2), ten female participants who have never used VR (A2B1), and four female participants who have ever used VR (A2B2). However, the GSR data that are used are only 5 participants for A1B1, 3 participants for $\mathrm{A} 1 \mathrm{~B} 2,2$ participants for $\mathrm{A} 2 \mathrm{~B} 1$, and 2 participants for A2B2. All participants are between 21-24 years old. Each participant is assigned to play the Beat Saber game for six songs using an Oculus Rift S type VR headset and GSR measuring instrument. Beat Saber itself is a rhythm game that combines visuals with the beat of the music and the controller in the game. Each song played has a difficulty level that increases until the end of the activity. Table 2 shows the songs played by the participants on Beat Saber.
Table 2. The Songs Used in The Experiment

\begin{tabular}{|c|c|c|c|}
\hline No. & Song Title & Duration & $\begin{array}{c}\text { Beat Per Minute } \\
\text { (BPM) }\end{array}$ \\
\hline 1 & 24K Magic & $0: 03: 47$ & 107 \\
\hline 2 & Payphone & $0: 03: 52$ & 110 \\
\hline 3 & Believer & $0: 03: 25$ & 125 \\
\hline 4 & Icy & $0: 03: 10$ & 125 \\
\hline 5 & Kill This Love & $0: 03: 07$ & 132 \\
\hline 6 & Dance Monkey & $0: 03: 30$ & 196 \\
\hline
\end{tabular}

Each participant holds a controller that functions as a sword in the game with a different color. The task given to participants is to hit the box that approaches according to the color and direction of the arrow in the box. Participants are also prohibited from hitting bombs and must avoid approaching walls.

Besides, the data collection for SSQ is also carried out. According to Kennedy et al. [21], SSQ consists of 16 indicators which are further divided into three subscales. There are nausea $(\mathrm{N})$, oculomotor $(\mathrm{O})$, and disorientation (D). The nausea subscale relates to the digestive system, the oculomotor subscale relates to the visual system, and the disorientation subscale relates to the body's balance system. Four categories are selected for each indicator, namely, none (not at all) with a value of 0 , slight (slightly experienced) with a value of 1 , moderate (experiencing) with a value of 2, and severe (very experiencing) which has a value of 3 . Table 3 shows the 16 indicators used in the SSQ and their groupings.

Table 3. SSQ Grouping

\begin{tabular}{|c|l|c|c|c|}
\hline No. & \multicolumn{1}{|c|}{ SSQ Symptoms } & $\mathrm{N}_{\mathrm{i}}$ & $\mathrm{O}_{\mathrm{i}}$ & $\mathrm{D}_{\mathrm{i}}$ \\
\hline 1 & General discomfort & 1 & 1 & 0 \\
\hline 2 & Fatigue & 0 & 1 & 0 \\
\hline 3 & Headache & 0 & 1 & 0 \\
\hline 4 & Eyestrain & 0 & 1 & 0 \\
\hline 5 & Difficulty focusing & 1 & 0 & 0 \\
\hline 6 & Salivation increasing & 1 & 0 & 0 \\
\hline 7 & Sweating & 1 & 0 & 1 \\
\hline 8 & Nausea & 1 & 1 & 0 \\
\hline 9 & Difficulty concentrating & 0 & 0 & 1 \\
\hline 10 & Fullness of the head & 0 & 1 & 1 \\
\hline 11 & Blurred vision & 0 & 0 & 1 \\
\hline 12 & Dizziness with eyes open & 0 & 0 & 1 \\
\hline 13 & Dizziness with eyes closed & 0 & 0 & 1 \\
\hline 14 & Vertigo & 1 & 0 & 0 \\
\hline 15 & Stomach awareness & 1 & 0 & 0 \\
\hline 16 & Burping & \multicolumn{3}{|c}{} \\
\hline
\end{tabular}

Nausea $\left(N_{x}\right)=9,54 \times \sum_{\mathrm{i}=1}^{16} N_{i} x_{i}$ Oculomotor $\left(O_{x}\right)=7,58 \times \sum_{\mathrm{i}=1}^{16} O_{i} x_{i}$

Disorientation $\left(D_{x}\right)=13,92 \times \sum_{i=1}^{16} D_{i} x_{i}$

Total $\left(T_{x}\right)=3,74 \sum_{\mathrm{i}=1}^{16}\left(N_{i}+O_{i}+D_{i}\right) x_{i}$

$N_{i}=$ nausea value of the $\mathrm{i}^{\text {th }}$ question $(0$ or 1$)$

$O_{i}=$ oculomotor value of the $\mathrm{i}^{\text {th }}$ question $(0$ or 1$)$

$D_{i}=$ disorientation value of the $\mathrm{i}^{\text {th }}$ question $(0$ or 1$)$

$x=$ Participant number

$i=$ Question number 


\section{RESULTS AND DISCUSSION}

The research is conducted by collecting data in the form of data on sweat levels, SSQ scores, and scores of activities played by participants. Data processing is carried out by performing descriptive calculations of the sweat level data, assessing SSQ, different tests, and affect testing. Table 4 shows the results of the descriptive statistics calculations for the GSR data.

Table 4. GSR Calculations (in microsiemens)

\begin{tabular}{|c|c|c|c|c|}
\hline & & Min & Max & Average \\
\hline \multirow{2}{*}{ Gender } & Male & 2,15 & 14,02 & 5,09 \\
\hline & Female & 1,76 & 9,52 & 3,62 \\
\hline \multirow{2}{*}{ Experience } & $\begin{array}{c}\text { Never } \\
\text { used }\end{array}$ & 1,87 & 14,02 & 4,54 \\
\hline & $\begin{array}{l}\text { Has } \\
\text { used }\end{array}$ & 1,76 & 9,52 & 4,68 \\
\hline \multicolumn{2}{|c|}{ AII } & 1,76 & 14,02 & 4,60 \\
\hline
\end{tabular}

Based on Table 4, it is found that male participants have higher minimum, maximum, and average scores than female participants. Meanwhile, participants who have never used VR have higher minimum and maximum scores compared to participants who have used VR. However, on average, participants who have never used VR have lower scores than participants who have used VR.

Next is SSQ data processing. Figure 4 shows a comparison diagram of the average score for each subscale and the total score for each category before and after the activity takes place.

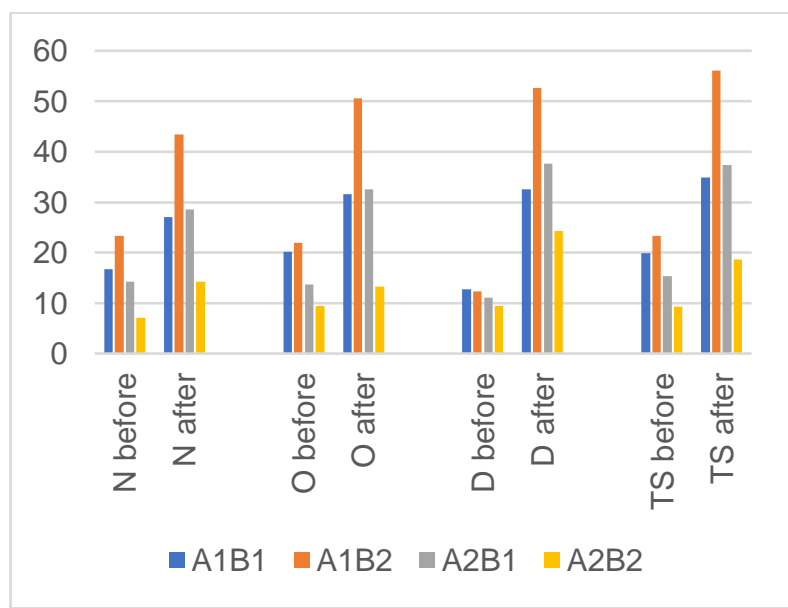

Figure 4. SSQ Results

Based on the SSQ results, it is found that participants coded A1B2 have the highest average value for all subscales and total scores except for the disorientation subscale before the activity. Meanwhile, participants coded A2B2 have the lowest average score for all subscales and total scores.

Furthermore, different tests are carried out on the GSR data and the total SSQ score. Table 5 shows the recapitulation of the results from the different tests.
Table 5. Recapitulation of Different Tests

\begin{tabular}{|c|c|c|}
\hline Indicator & P-value & Results \\
\hline $\begin{array}{c}\text { Average of GSR before } \\
\text { activity with at the time } \\
\text { of activity }\end{array}$ & 0,043 & $\begin{array}{c}\text { There is a } \\
\text { difference }\end{array}$ \\
\hline $\begin{array}{c}\text { Average of GSR during } \\
\text { activity and after activity }\end{array}$ & 0,025 & $\begin{array}{c}\text { There is a } \\
\text { difference }\end{array}$ \\
\hline $\begin{array}{c}\text { Average of GSR before } \\
\text { activity with after } \\
\text { activity }\end{array}$ & 0,209 & $\begin{array}{c}\text { There is no } \\
\text { difference }\end{array}$ \\
\hline $\begin{array}{c}\text { Total SSQ score before } \\
\text { activity and after activity }\end{array}$ & 0,000 & $\begin{array}{c}\text { There is a } \\
\text { difference }\end{array}$ \\
\hline
\end{tabular}

Based on Table 5, it is found that only the average GSR before and after the activity does not have a difference in average. This indicates that there is indeed an increase in sweat levels and changes in body condition because of using VR.

Furthermore, the influence test for gender and experience factors is carried out on the GSR, SSQ, and score data. Table 6 shows a recapitulation of the influence test.

Table 6. Recapitulation of Influence Tests

\begin{tabular}{|c|c|c|c|}
\hline Factor & Response & P-value & Results \\
\hline \multirow{6}{*}{ Gender } & $\begin{array}{c}\text { Average of } \\
\text { GSR }\end{array}$ & 0,174 & No effect \\
\hline & Nausea score & 0,213 & No effect \\
\hline & $\begin{array}{l}\text { Oculomotor } \\
\text { score }\end{array}$ & 0,511 & No effect \\
\hline & $\begin{array}{c}\text { Disorientation } \\
\text { score }\end{array}$ & 0,578 & No effect \\
\hline & Total score & 0,201 & No effect \\
\hline & $\begin{array}{c}\text { Average of } \\
\text { activities score }\end{array}$ & 0,249 & No effect \\
\hline \multirow{6}{*}{ Experience } & $\begin{array}{c}\text { Average of } \\
\text { GSR }\end{array}$ & 0,465 & No effect \\
\hline & Nausea score & 0,004 & Effect \\
\hline & $\begin{array}{l}\text { Oculomotor } \\
\text { score }\end{array}$ & 0,015 & Effect \\
\hline & $\begin{array}{c}\text { Disorientation } \\
\text { score }\end{array}$ & 0,039 & Effect \\
\hline & Total score & 0,772 & No effect \\
\hline & $\begin{array}{c}\text { Average of } \\
\text { activities score }\end{array}$ & 0,152 & No effect \\
\hline
\end{tabular}

Based on the results of the influence test, it is found that only the experience factor using VR affects the SSQ score for the entire subscale. This indicates that the use of VR affects the digestive system, vision system, and balance system of the participants' bodies. Because there are influences on nausea, oculomotor, and disorientation subscales, a significance test is carried out to determine whether the differences in influence are significant or not. 
Table 7 shows the results of the significance test carried out.

Table 7. Significance Test Results

\begin{tabular}{|c|c|c|}
\hline Indicator & P-value & Results \\
\hline Nausea subscale & 0,0046 & $\begin{array}{c}\text { Significantly } \\
\text { different }\end{array}$ \\
\hline $\begin{array}{c}\text { Oculomotor } \\
\text { subscale }\end{array}$ & 0,0154 & $\begin{array}{c}\text { Significantly } \\
\text { different }\end{array}$ \\
\hline $\begin{array}{c}\text { Disorientation } \\
\text { subscale }\end{array}$ & 0,4029 & $\begin{array}{c}\text { Not significantly } \\
\text { different }\end{array}$ \\
\hline
\end{tabular}

Based on the results of the significance test, it is found that there are significant differences between participants who have never used VR and participants who have ever used VR for the nausea subscale and the oculomotor subscale. However, for the disorientation subscale, there is no significant difference.

After processing the data, an analysis of the results of the processing are carried out. There is a difference in the amount of data between the GSR and SSQ. This happens because the sensor on the GSR fails to read sweat levels and some participants move too actively so that the tool is released while doing the given task.

Based on the results of GSR data processing, it is found that most of the participants have high sweat levels at the beginning of the activity. It presumably happens because at the beginning of the activity the participants' bodies are still trying to adapt to the virtual environment and the activities carried out even though there are participants who have used VR before. This is because the VR devices that have been used by participants are not the same as those used in the research, and all participants have never played the Beat Saber game. Besides, it is also found that there is a fairly high increase in sweat levels around 15 to 20 minutes after the activity takes place, where at this time cybersickness appears.

Based on the results of the influence test, it is found that gender does not affect cybersickness either objectively (GSR) or subjectively (SSQ). These results are like those of Knight and Arns [15], Ling et al. [17], and Sagnier et al. [18] which stated that gender did not affect cybersickness. As for the experience factor, it is found that it does not affect cybersickness based on the GSR results, but it does affect cybersickness. The difference in results between objective and subjective measurements is thought to occur due to the types of games used and the definition of experiences using VR where in this study participants who have ever used VR at least once are considered experienced participants. There is an assumption that the sweat produced by the participants is a result of physical activity during the game. However, based on the SSQ score, it is found that there is an increase in the score between before and after the activity. This indicates that the condition of the body has indeed changed due to exposure to cybersickness. Besides, according to Rangelova et al. [22], physical activity correlated with cybersickness. So that the sweat produced by the participants is due to cybersickness.
In this study, the use of GSR is not appropriate as the only physiological measurement tool in measuring cybersickness, while SSQ is appropriate. This is because SSQ has been used for a long time in many studies so that its credibility is higher than GSR which has not been widely used in research. Also, SSQ has more indicators than GSR. In the SSQ, 16 different indicators can be observed, while in the GSR there is only one indicator, namely sweat. Everyone's sweat production is different and it depends on his body condition, such as a history of sports habits, clothes used, body mass, genetic, age, and gender [23].

In this study, a sophisticated VR headset is used, namely the Oculus Rift $\mathrm{S}$. This type of headset is series of 2019 that has undergone improvements where the optics are modified to reduce the screen door effect (SDE). SDE can cause dizziness to users because the view that is seen by the user is as if it is visible from the net [24]. This study also uses an Intel Core i7 $8700 \mathrm{~K}$ processor, $32 \mathrm{~GB}$ of RAM, and a graphics processing unit card type Nvidia GTX 2070. According to Jerald [25], the higher the CPU speed and the higher the GPU capability, the lower the risk of cybersickness. According to Beat Games [26], the developer of the Beat Saber game, there are system requirements that must be met to be able to use the Beat Saber game, namely an Intel Core i5 Sandy Bridge processor or equivalent, a minimum of $4 \mathrm{~GB}$ of RAM, and a minimum GPU card of Nvidia GTX 960 or equivalent. All instruments used in the study have a quality above the requirements given. Therefore, the symptoms of cybersickness experience by the participants are not due to the equipment used, but the individual himself or herself.

Some recommendations are given based on the research results. The developer should create a virtual environment that resembles the real world as much as possible so that the user does not experience a sensory and perceptual mismatch between the visual system and the vestibular system. During the data collection, participants who cannot distinguish between the real world and the virtual world feel fewer negative effects from using VR compared to participants who have never used VR who feel the real world and the virtual world are very different.

To users, it is appropriate to use a device that has a minimum specification equivalent to the requirements given by the VR software. Low specifications can cause delays in users which makes the view different from what the user feels himself. Besides, it is also recommended for users not to use VR for more than 15-20 minutes.

\section{CONCLUSIONS}

The conclusion that can be drawn based on the results of data processing and the analysis carried out is that the experience of using VR affects the digestive system, visual system, and coordination system of the user. Qualitatively, there is an increase in high sweat levels at the beginning of the activity as the body's reaction to adapt to the virtual environment and activities carried out and the increase in sweat levels returns around 15 to 20 minutes after the activity takes place at which time the symptoms 
of cybersickness are thought to appear. The advice that can be given to the developer is to create a virtual environment that resembles the real world as much as possible to avoid a sensory and perceptual mismatch between the visual system and the vestibular system. Users themselves are advised to use a device that at least matches the existing specifications and does not use VR for more than 15 to 20 minutes.

The next suggestion is aimed to make readers or other researchers carrying out similar research do better research. It is better to use SSQ as a measure of cybersickness and not use GSR as the only physiological measurement tool. The researchers can use other physiological measuring tools, such as a tool to measure heart rate or measure brain waves so the results obtained are more representative. Besides, it is also recommended to use more than one game or activity so that it can be seen whether the body reaction produced by the participants is a reaction due to mental workload or physical workload. The definition of participants who have ever used VR is also changed not only once at least to avoid bias in the data. If one-time use of VR is considered an experienced category, it will be difficult to differentiate between those who have and have not used VR.

\section{REFERENCES}

[1] K. Hillis, Digital sensations: space, identity, and embodiment in virtual reality, vol. 18, no. 2 . Minneapolis: University of Minnesota Press, 2001.

[2] Statista, "Virtual Reality (VR) Market Revenue in The United States From 2014 to 2025," 2018. [Online].

Available: https://www.statista.com/statistics/784139/virtual -reality-market-size-in-the-us/\#statisticContainer.

[3] Statista, "Forecast for The Number of Active Virtual Reality Users Worldwide 2014 to 2018," 2017. [Online]. Available: https://www.statista.com/statistics/ 426469/active-virtual-realityusersworld wide/.

[4] Newzoo, “Indonesian Games Market," 2015. [Online]. Available: https://newzoo.com/insights/infographics/newzoo -summer-series-21-indonesian-games-market/.

[5] G. Ashton, "Guide to the SEA Games Esports Event: Titles, Nations, and Major Players," 2019. [Online]. Available: https://esportsobserver.com/sea-games-esportsguide/.

[6] Globalwebindex, "Esports Trends Report 2018," 2018. [Online]. Available: https://www.globalwebindex.com/reports/esportstrends-2018\#download.

[7] M. E. McCauley and T. J. Sharkey, "Cybersickness: Perception of Self-Motion in Virtual Environments," Presence Teleoperators Virtual Environ., vol. 1, no. 3, pp. 311-318, 1992, doi: 10.1162/pres.1992.1.3.311.

[8] J. Barrett, "Side effects of virtual environments: A review of the literature," Inf. Sci. Lab., p. 60, 2004, [Online]. Available: https://apps.dtic.mil/docs/citations/ADA426109\% 0Ahttp://dspace.dsto.defence.gov.au/dspace/bitstr eam/1947/4079/1/DSTO-TR-1419 PR.pdf.

[9] K. M. Stanney, R. S. Kennedy, and J. M. Drexler, "Cybersickness is not simulator sickness," Proc. Hum. Factors Ergon. Soc., vol. 2, pp. 1138-1141, 1997, doi: 10.1177/107118139704100292.

[10] D. M. Johnson, "Introduction to and Review of Simulator Sickness Research," Arlington, 2005.

[11] E. C. Regan, "Some evidence of adaptation to immersion in virtual reality," Displays, vol. 16, no. 3 , pp. 135-139, 1995, doi: 10.1016/01419382(96)81213-3.

[12] F. Biocca, "Will Simulation Sickness Slow Down the Diffusion of Virtual Environment Technology?," Presence Teleoperators Virtual Environ., vol. I, no. 3, pp. 334-343, 1992, doi: 10.1162/pres.1992.1.3.334.

[13] S. A. Clemes and P. A. Howarth, "The menstrual cycle and susceptibility to virtual simulation sickness," J. Biol. Rhythms, vol. 20, no. 1, pp. 7182, 2005, doi: 10.1177/0748730404272567.

[14] G. D. Park, R. W. Allen, D. Fiorentino, T. J. Rosenthal, and M. L. Cook, "Simulator sickness scores according to symptom susceptibility, age, and gender for an older driver assessment study," Proc. Hum. Factors Ergon. Soc., pp. 2702-2706, 2006, doi: 10.1177/154193120605002607.

[15] M. M. Knight and L. L. Arns, "The relationship among age and other factors on incidence of cybersickness in immersive environment users," Proc. - APGV 2006 Symp. Appl. Percept. Graph. Vis., p. 162, 2006, doi: 10.1145/1140491.1140539.

[16] P. Gamito et al., "Presence, immersion and cybersickness assessment through a test anxiety virtual environment.," Annu. Rev. CyberTherapy Telemed., vol. 6, pp. 83-90, 2008.

[17] Y. Ling, H. T. Nefs, W. P. Brinkman, C. Qu, and I. Heynderickx, "The relationship between individual characteristics and experienced presence," Comput. Human Behav., vol. 29, no. 4, pp. 1519-1530, 2013, doi: 10.1016/j.chb.2012.12.010.

[18] C. Sagnier, E. Loup-Escande, and G. Valléry, "Effects of gender and prior experience in immersive user experience with virtual reality," Adv. Intell. Syst. Comput., vol. 972, pp. 305-314, 2020, doi: 10.1007/978-3-030-19135-1_30.

[19] M. Biosystems, "Minfield eSense Skin Response Manual Version 4.2.8," 2019. [Online]. Available: https://www.mindfield.de/phocadownload/eSense /

English/esense_Skin_Response_Manual_EN.pdf.

[20] G. Moss, "How to Play 'Beat Saber': Top 12 Tips $\&$ Tricks (From the Pros)," 2019. [Online]. Available: https://www.vrfitnessinsider.com/top12-beat-saber-tips-tricks/. 
[21] R. S. Kennedy, N. E. Lane, K. S. Berbaum, and M. G. Lilienthal, "Simulator Sickness Questionnaire : An Enhanced Method for Quantifying Simulator Sickness Simulator," Int. J. Aviat. Psychol., no. 3:3, pp. 203-220, 1993, doi: 10.1207/s15327108ijap0303_3.

[22] S. Rangelova, D. Motus, and E. André, "Cybersickness Among Gamers: An Online Survey," Adv. Intell. Syst. Comput., vol. 973, pp. 192-201, 2020, doi: 10.1007/978-3-030-20476$1 \_20$.

[23] L. B. Baker, "Physiology of sweat gland function: The roles of sweating and sweat composition in human health," Temperature, vol. 6, no. 3, pp. 211-259, 2019, doi: 10.1080/23328940.2019.1632145.

[24] J. Nguyen, C. Smith, Z. Magoz, and J. Sears, "Screen door effect reduction using mechanical shifting for virtual reality displays," in Proceedings SPIE 11310, Optical Architectures for Displays and Sensing in Augmented, Virtual, and Mixed Reality (AR, VR, MR), 2020, p. 22, doi: 10.1117/12.2544479.

[25] J. Jerald, The VR Book: Human-Centered Design for Virtual Reality. Morgan \& Claypool, 2015.

[26] B. Games, "Beat Saber," 2019. [Online]. Available:

https://store.steampowered.com/app/620980/

Beat_Saber/. 